\title{
About Competitive Strategy in Companies
}

\author{
D. SĂVESCU \\ Transilvania University of Braşov, Romania
}

\begin{abstract}
Paper presents some aspects regarding the strategy made by companies, the effort of the top management to be profitable. Beginning with some definitions, in the other hand it is presented from a synergetic point of view, a study case for company performance, in the way to be competitive, durable, with good clients, stakeholders. There are also presented ways to be adopted to open the excellence road.
\end{abstract}

KEYWORD: Management; Strategy; Synergy; Competitiveness; Profitableness

\section{INTRODUCTION}

Strategy is a very usual subject in management theory and in practice. Identify national and international competition is an engine that bring to the forefront of concerns strategy specialists. What the customer buys from a vendor is a specific offer. The strategy aims to shape this offer as to make it possible to present the firm and attractive preferred buyer. The overall strategy of the firm decides which ones will make firm offers portfolio as a whole, to be profitable and will pave the way towards excellence.

\section{COMPETITIV STRATEGY}

There are numerous definitions assigned strategy, some include the objectives, others consider only way forward, resources and environment, but always consider the internal situation of the company. Strategy is a long-term action plan, which is achieved through perseverance and continuity of effort, requiring the existence of an inverse connection, strategic feedback as a means to constantly adapt to change.

H. Mintzberg presents a group of definitions of strategy:

- A perception designating a predetermined course of action to solve a problem;

- A coherent set of behavioral action plan;

- Positioning the company in its life;

- Perspective involves the establishment of a position to a problem;
- Perception of reality is reflected in the actions to market, technology etc.

M. Porter, using the term "generic strategy" shows that the strategy is to "specify the fundamental approach to achieving competitive advantage sought by the company, which provides the context of actions taken in each functional area."

There are some steps to follow such as:

1. Establishing mission;

2. Setting goals;

3. Allocation of resources;

4. Fulfilling the mission, accepting the solution on time;

5. Lessons corrections.

What determines the strategy is the organization's mission. The mission explains why the company exists, what activates particular purpose. Thus the strategy shows what needs to be done so that the mission indicates on which way you go so that you gain competitive advantage.

In setting goals are taken into account: overall objectives, functions or divisions, departments, profit centres, and individual subunits.

Obviously we can not talk about strategy without seeing the resources involved, technological resources, human, financial, management.

Alternatives on the development of the company are influenced directly by the ability of managers to invest, take risks. As well said Alvin Toffler, "the first risk factor is ignoring it" is the duty of managers to consider very carefully the variety of solutions that will adopt the most appropriate measures available, possible at the time, so that fulfil their mission, according to the strategy.

Figure 1 shows the Profitability-Risk Matrix, which allows positioning of the company in one of 
the four cases, and there is obviously a completely unacceptable option for profitability is low, so the risk.

\begin{tabular}{|c|c|c|}
\hline Profitability & High & Low \\
\hline High & $\begin{array}{c}\text { Aggressive } \\
\text { organizations } \\
\text { (excess risk) }\end{array}$ & $\begin{array}{c}\text { Unacceptable } \\
\text { situation }\end{array}$ \\
\hline Low & Ideal situation & $\begin{array}{c}\text { Prudent } \\
\text { organizations } \\
\text { (prudent risk) }\end{array}$ \\
\hline
\end{tabular}

Figure 1. Profitability - Risk Matrix; R - R

The main types of strategies used by companies are:

- Growth strategies;

- Strategies for;

- Defensive strategies;

- Restriction strategies;

- Combining strategies.

Strategies of firms are influenced by many factors, and marketing is the basic support for defining strategy.

\section{GAINING COMPETITIVENESS HAVING AS SUPPORT A PERFORMANT STRATEGY}

Company management approach developed ways to cope with increasing complexity, novelty and unforeseen circumstances, given the increasing turbulence in the competitive market. The future is becoming less predictable, so it requires competitive management systems, sophisticated, each completing or developing the previous ones.

Their evolution can be grouped into four stages:

- Management by controlling performance after implementation; it is preferred in the case of slow changes;

- Management extrapolation when change is accelerating, but the future can possibly be approximated by extrapolating previous statements;

- Management by anticipation, since discontinuities occur but change, although rapid, allows anticipating and formulating a response in real time;

- Management by rapid responses and flexible, which is rising given that a number of important phenomena presents a development too fast to allow for timely anticipation.

In fact the way that it has crossed the management team in establishing an efficient strategy is a winding road, the visionary look is influenced by turbulence risk, with turning points, learn from mistakes, corrections on the fly, adoption the "best " route to achieve the goal competitiveness (see figure 2).
Directly, firm performance depends on the quality of the strategy applied. Basic characteristics of a competitive strategy are:

- Foreshadowing the future (3-10 years) of this special involve risk and uncertainty;

- Statement of the purpose (mission - objectives), clarifying the concept of the evolution of the company, which differs from other similar firms, and clear direction to what is moving development efforts;

- Target essentials of major developments, technological mutation, managerial, financial, commercial, company that provides balance and prosperity in turbulent environmental conditions;

- The design firm as a system and ensuring its synergy;

- Ensuring a competitive behaviour by constructing a mechanism that maintains an organizational learning process and ensuring permanent developments culture (Harrison, 1997).

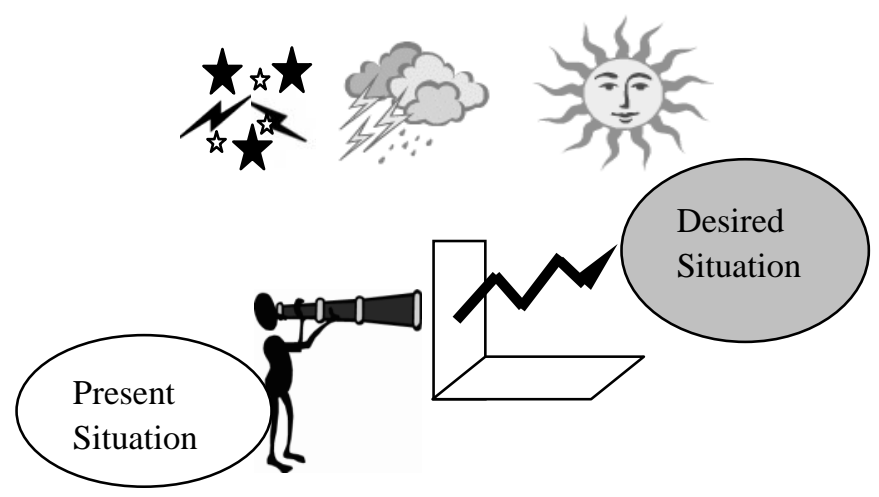

Figure 2. Critical road of strategy (Dăneţ, 2006)

It can be appreciated that the main requirements for the development strategy of the company require consideration of the following:

- Influences government: taxes, legislation, controls;

- Organization and processes: current situation, the clarity of objectives, policies and procedures successfully applied earlier or adapted to new requirements, existing motivational system capacity referral opportunities, the support of advisors / consultants;

- Personal philosophy of managers, their actual style of leadership (authority), and the values and priorities of stakeholders (interested parties), the efficient delegation of managerial skills in general;

- Organizational culture, skills, attitude towards work, motivation;

- Technology: cost, availability and rate of aging / obsolescence of equipment;

- Customers: preferences and needs actual purchasing power, stability of demand, the attitude towards the company; 
- Attitudes competitors: aggression, mood towards cooperation;

- Resources: accessibility and cost;

- General socio-economic conditions: the economic situation, the situation of peace or armed conflict, public opinion, media, media.

To quickly achieve objectives, taking into account the above, the formation of multi-disciplinary teams practice, able to push, to harmonize the activity of introducing and adapting the strategy to the organization's culture and demands of the moment.

According to some authors (Bragg, 2005) are landmarks that can be suggested to adventurers managers, tempted by different motivations, high profits and quick, personal prestige and so on, such as:

Any strategy, even one partially erroneous is better than lack of strategy entirely. Any strategy is perfect from the beginning, especially when developed by "amateurs", but is considered as a basis for correction along the way improved;

- Fostering the development of appropriate corporate culture, being a capital and indispensable condition for the development and implementation of the strategy;

- Draw up the strategy with staff, in consultation with a range of masses as specialists within or outside the firm;

- Foreshadowing the future, anticipating future developments of the company, is a difficult operation even for high performance firms in developed countries.

The strategy conceived and implemented according to situation and context.

\section{SINERGY INVOLVED IN ESTEBLISHING THE COMPANY STRATEGY}

Synergetic is the science of self-organization and self-structuring systems, irrespective of their nature, based on collaboration, cooperation organic constituent components and subsystems (is a definition provided by Professor Herman Haken of the University of Stutgard). Based on this, we can say that synergistic aims phenomena occurring in complex systems, open specific living world and social systems, which manifests micro scale, the effect of synchronous cooperation Macro scale, the individual components (Dawson, 1996).

Businesses operate as coherent assemblies organized in order to achieve positive economic results of profit.

Components of companies include: material elements, communication networks, organizational structures, pressure groups who have not a physical support, but can exert an influence on the socioeconomic environment.
It may take the study of a set of elements that define the companies:

- Work (tools, Tools/Checkers/ Devices (SDV), Measurement and Control Devices (AMC), utilities - water, power, heat, manufacturing logistics);

- Technological area (system jobs, communications, information flow, shared facilities);

-Functional subsystem (workshop, division, functional compartment, department, factory);

- The company and the company operating in a global economy (micro, SME, large enterprise, corporation, multinational, etc.).

- All companies that make up a collaborative network or belong to an industry (oriented business association like, Clusters etc.).

Synergetic attracts more attention competent and committed managers to achieve a competitive advantage for the firm to improve strategic effort.

Equation symbol of positive synergy, showing that business portfolio worth more than the business itself, taken part by part is " $2+2=5$ ". Synergy has zero equation " $2+2=4$ ", in which case there is only a simple arithmetic summation, grouping of elements having a positive effect on business, but an accumulation of items that can cause distortions in communication, coordination, control. Negative synergies written as $" 2+2=3$ " are derogatory and meet, for example, personal excess (large expenditures on wages), agglomeration SDV, AMCs expensive and not in amortized quickly a large volume of products sold and collected, or raw materials expensive, purchased from a vendor uncertain, unreliable.

Through such analysis managers can decide on the strategy to be followed, the aim being competitive products sold quickly and achieve desired profit, assuming this goal intense creative effort, multiple skills. Two or more strategies in synergy relationship are an important part of sharedcost, know - how and skills, values and goals of organizational culture grouped together, with the goal clearly defined, to obtain sustainable competitive advantage over competition.

\section{ABOUT TECHNOLOGICAL VIGILENCE}

Ensure technology is a selective method, permanent and organized to gather information from outside the organization, analyze it and convert it into knowledge in order to make decisions with a low hazard risk and be able to anticipate the changes that looming.

Technological vigilance is a systematic and organized effort of an organization to observe, receive, analyze, disseminate and retrieve punctual and thorough information about certain events in the 
economic, technological, social or business information are important because they can involve an opportunity or a this threat (Săvescu, 2012).

Technological vigilance enables the development and fulfillment of role has intelligence, through appropriate and accurate distribution of information and communication within an organization.

Use information and knowledge in decisionmaking is the competitive or business intelligence [1].

Also, technological vigilance is both a process and a product, i.e. a set of information on which decisions are made. It thus reversed the traditional trend of using raw data priority $-80 \%$, resulting information analysis - $15 \%$ and high added value products (analysis + validation) - 5\%, redirecting it towards value information products added: technological vigilance means analysis and validation - 55\%, information - 25\%, $20 \%$ raw data.

It helps to increase market competitiveness through a better understanding of the competitive environment and becomes extremely useful for the following reasons:

1 enables continuous information and complex managers on market actors that evolve when vital business rate increases rapidly;

2 limit information overload; processes considering an analyze of information and determining what is important;

3 is well adapted to the development of global economy, today, doing business is no longer think in terms of geographical boundaries and its products can support managers in detecting new competitors or those who intend to enter the market;

4 help to increase market share at the expense of the organization's competitors in areas where current competition is very aggressive;

5 help the organization to quickly implement policy decisions made under the pressure of public opinion;

6 help the organization to cope with rapid technological change, monitoring technological change is vital for survival;

7 technological innovation can be the difference between success and failure, may increase or decrease in market share etc.

Technological vigilance must be focused on certain aspects of a business and its environment, for reasons of cost and time. No business can devote to study and / or to outsource all aspects. As for resources, an organization must monitor according to its strategic objectives.

Systematize the need to ensure a method by allowing an operation in regular monitoring of both the business events that may affect the function and operation of the sleep itself. Organizations should consider their environment, and to apply methods that properly defines and outlines the functions of supervision and guarantee the quality, regularity and homogeneity.

Technological vigilance must organize an elastic structure, supported in an internal organization, decentralized, based on the creation and use of both physical networks and virtual ones, and decisionmaking at multiple levels, having an efficiently and feedback systems.

\section{CONCLUSIONS}

It can be appreciated that the establishment of a firm's strategy is part of its survival in the market. A competitive strategy is the result of managerial work, noting that management must be competitive, tailored to the current high capacity to change, to launch a number of projects, a broad portfolio that can always be applied according to customer requirements.

"Dreams and desires are not objectives, only after they have been put on paper" (Anonymous)

Obviously not be neglected risk, but the risk control leads to profit.

Any strategy adopted is better than its absence, noting that management involved has inherent error correction capability.

"At all times the best thing you can do is to do something.

The worst thing is to do nothing "(Roosevelt)

\section{REFERENCES}

[1] Bragg, A.2005. Developing new business ideas. Prentice Hall London, 2005

[2] Charrier.J.C. 1989. Maîtriser l'organisation industrielle. Les Editions d'Organisation, Paris.

[3] Danet, A. 2006. Managementul proiectelor (Project management). Diz Tipo, Braşov, Romania.

[4] Dawson, M. 1996. Analysing Organisations. Mc. Millan Press, London.

[5] Harrison, J. 1997. Supergrowth Companies, Entrepreneurs in Action, Butteworth Heinemann, Oxford.

[6] Iancu, A. 2003. Dezvoltarea economică a României (Economic Development of Romania), Bucureşti, 2003.

[7] Kotler, Ph. 1999. The Marketing of Nations. Free Press, New York

[8] Popescu, R. 2008. Firma industrială de la cunoaştere la excelenţă (Industrial Company from knowledge to excellence), Ed. AGIR, Bucureşti.

[9] Săvescu, D. 2012. "Research for Business" - a New Concept and a Case Study, ICASS 2012, Vol 2, pp. 339344, Kuala Lumpur, Malaysia 